\title{
Functional exercises improve quality of life of obese depressed women: a case report study.
}

\author{
João Francisco Barbieri'1, 2, Daniela Picerno1', Débora Tomazelli1, Jamile Baptista Palamedi', Vanessa Érika Guitte', \\ Shirko Ahmadi²
}

\begin{abstract}
Background: Depression is characterized by abnormal affective manifestations. This pathology is more frequent among women and is aggravated with the overweight/obesity. Regular exercises have been shown to combat the manifestations of depression, as well as to increase active behavior and improve the morphology. Objectives: This study aimed to evaluate the effect of functional training on morphology, physical activity level and quality of life of obese women with depression. Methods: Four women with mean aged $32.5 \pm 10.6$ underwent 2 months of functional training, which performed twice a week, each session 1-hour training. Participants were evaluated in 3 times (T): T1) pre-test; T2) at the end of first month (mid-test); and T3) at the end of the second month (post-test). Results: We observed significant changes for the waist circumference variable, and presented a reduction in mid-test and post-test, in relation to the pre-test $(p<0.05)$. No changes were observed for the variables weight and BMI. It was observed a significant increase in the level of physical activity, with the mid-test and post-test in relation to the pre-test (mid-test: $p<0.05 ; p 0 s t-t e s t: p<0.01$ ). All the indices evaluated by the SF-36 questionnaire showed improvement at mid-test and post-test relative to the pre-test ( $p<0.05)$. Conclusions: The present study suggests that engagement in functional training programs provides a significant improvement in aspects related to quality of life and depression, as well as an increase in the level of physical activity, even in the absence of weight reduction.
\end{abstract}

Key Words: Physical Exercise; Depression; Functional Training; Obesity.

\section{INTRODUCTION}

Depression is characterized by abnormal affective manifestations that have their variances in relation to their intensity and symptoms duration ${ }^{(1-3)}$. Depression is intrinsically linked to low self-esteem, lack of pleasure, defeatist thoughts, social isolation and lack of appetite; also often compromises motor and cognitive abilities, which result in decreasing quality of life $(\mathrm{QOL})^{(4,5)}$. Epidemiological research in multicultural reports that women are twice as likely to develop depression than $\mathrm{men}^{(6)}$. Considering obesity showed that the likelihood of women developing depression increase even more, whether due to perception of self-image ${ }^{(7,8)}$ or metabolic factors influenced by fat excess accumulation ${ }^{(9,10)}$. Other different variables such as age, residence area, socio-demographic situation, social status and marital status, may also be associated with the onset of depression ${ }^{(1,11)}$.

Depression significantly affects the $\mathrm{QOL}^{(12)}$ and is related to decreasing in active behavior and increasing in sedentary lifestyle levels, in which may exacerbate the symptoms of depression ${ }^{(13)}$. Several forms of treatment have been developed to combat this pathology, in which among non-pharmacological treatments the regular practice of physical exercises is more highlighted ${ }^{(14,15)}$. The adherence and maintenance of physical activity lead to benefits for people with depression, which feelings of pleasure, met expectations and improvement in self-determination factors are examples of them ${ }^{(13,16)}$. Some studies have demonstrated that physical exercise has the potential to provide improvements in various symptoms of depression ${ }^{(17,18)}$, improving QOL and the level of spontaneous physical activity ${ }^{(19)}$ which being used as a non-pharmacological treatment. Weight loss and morphological changes caused by regular exercise also have a positive influence on depression ${ }^{(20,21)}$. As a type of physical exercise, functional training (FT) is characterized as a multicomponent exercise, which several joints and muscle groups are involved in a single exercise for improving transposition of the exercise to daily living tasks ${ }^{(22)}$. The FT is an alternative for conventional training, which presenting good results for adherence and morphological changes related to physical exercise, such as loss weight ${ }^{(23)}$, decrease of cardiac pathologies, and decrease of waist circumference (WC) ${ }^{(24)}$.

Taking into account the increase in cases of depression and obesity among women ${ }^{(6)}$, and the beneficial effects of the

\footnotetext{
Corresponding author: João Francisco Barbieri. Address: Department of Physical Education, University of Campinas, Brazil; Phone: 11 994914733. Email: joao.francisco.barbieri@gmail.com 1 Department of Physical Education - Centro Universitário Max Planck (UNIMAX), Indaiatuba, SP, Brazil.

2 Department of Physical Education, Universidade Estadual de Campinas (UNICAMP), Campinas, SP, Brazil.
}

Financial support: Nothing to declare.

Submission date 17 February 2019; Acceptance date 29 March 2019; Publication date 03 December de 2019 
exercise ${ }^{(13)}$, we believe in the importance of understanding how the FT effect on both of them. Therefore, this study aimed to evaluate the effect of functional training on the QOL, physical activity level, Body Mass Index (BMI) and waist circumference (WC) of obese women with depression diagnostic.

\section{METHODS}

\section{Participants}

Four adult women (age $=32.5 \pm 10.6$ years, height $=1.59 \pm 0.05 \mathrm{~m}$ ), were evaluated. All the participants were recruited, evaluated and trained in a gym in Indaiatuba city, São Paulo, Brazil. As inclusion criteria, the participants must have presented obesity (BMl>30) and medical report confirming a condition of depression. The intervention was composed by functional exercises that duration two months, with two weekly sessions lasting one hour each session. The evaluations were composed by BMI, WC measures and questionnaires in 3 different times ( $T$ ). The participants were evaluated at: $T 1$ ) the pre-intervention (pre-test), T2) at the end of the first month (mid-test), T3) at the end of the second month (post-test). Data were collected following the ethical principles as stated in the declaration of Helsinki proposed by the world association of physicians. The project behind this study was submitted and authorized by the research ethics committee of the Municipal Hospital Dr. Mário Gatti under protocol No 2.847.951.

\section{Consent}

Written informed consent was obtained from the patient for publication of this Case report and any accompanying images. A copy of the written consent is available for review by the Editor of this journal.

\section{BMI and WC measures}

Body weight was measured by a digital scale (Omron-HBF514). Body height and WC was measured by a tape, following the recommendations of the literature for $W^{(25)}$. The BMI was calculated as weight in kilograms divided by height in meters squared.

\section{Questionnaires}

The IPAQ (International Physical Activity Questionnaire) short form questionnaire was used in this study ${ }^{(26)}$. This questionnaire measures indirectly the level of physical activity during a week. The formula by Barbara Bushman ${ }^{(27)}$, was used to express IPAQ results in kilocalories that spent per week. Also we used the SF-36 questionnaire, which evaluates the QOL and perception of depressive syndrome from the participants' point of view. The SF-36 evaluates following eight health concepts: functional capacity, physical appearance, pain, general health, vitality, social aspects, emotional aspects and mental health ${ }^{(28)}$. All the questionnaires were applied in the three times of evaluations.

\section{Physical training}

The program comprised of two one-hour sessions per week, over 8 weeks. Each session incorporated:

- 20 minutes of general warm up: Stretching exercises of lower, upper limb muscles and aerobic exercises (walking): subjects worked at their own pace.

- The main part of session (functional training) was divided in 3 blocks of 10 minutes for each one, which included: 1) lower limbs exercises; 2 ) upper limbs exercises; and 3 ) core muscles exercises (abdominal and lumbar region) were performed. During exercises execution the rating of perceived exertion (RPE) responses were used, to predict the internal load and exercise intensity of participants ${ }^{(29)}$.

- Sessions finished with a 10-minute cool-down period and relaxation exercises.

\section{Statistical analysis}

Data are presented as mean and standard deviation. Normality of the data was verified through the Shapiro-Wilk test ${ }^{(30)}$. The One-way ANOVA test was used to compare the three times (pre $x$ mid $x$ post) tests. When the interaction effect was found, the Bonferroni post hoc was used. The significance level which used was $p \leq 0.05$. All statistical analysis was carried out with IBM SPSS Statistics 23.0.

\section{RESULTS}

During the two months physical training period, no significant differences were observed in relation to the BMI $(p=0.45)$ and body weight $(p=0.14)$ variables. It was a significant difference in WC, and the post hoc showed a significant reduction in mid-test $(p=0.04)$ in relation to pre-test, which this reduction was maintained at the post-test $(p=0.002)$. There were no significant differences between moments mid-test and post-test for WC $(p=0.06)$. The values can be observed in table 1 .

All dimensions of the SF-36 questionnaire presented significant differences which include: physical aspects, pain, general health status, vitality, social aspects and mental health. All of these dimensions presented similar dynamics, with improvement from pre-test to mid-test $(p<0.05)$ and maintenance these significant differences from mid-test to post-test $(p<0.05)$. No significant difference between mid-test and post-test was identified for any of the SF-36 dimensions ( $p>0.05)$. For the Emotional Aspects dimension, the student t-test was used to make a direct comparison between pre-test and post-test, since the mid-test did not present any variance (all responses reached the maximum score of 100). 
Table 1. Morphological variables

\begin{tabular}{cccc}
\hline Variables & Pre-test & Mid-test & Post-test \\
\hline Weight $(\mathrm{Kg})$ & $96.9 \pm 24.5$ & $88.4 \pm 23.1$ & $85.8 \pm 23.4$ \\
BMI (kg/m²) & $34.6 \pm 6.6$ & $34.2 \pm 8.2$ & $36.5 \pm 8.8$ \\
WC $(\mathrm{cm})$ & $105.5 \pm 27.2$ & $100.8 \pm 26^{*}$ & $96.2 \pm 26.4^{*}$ \\
\hline
\end{tabular}

Note: BMI- body mass index, WC- waist circumference. ${ }^{*} \mathrm{p} \leq 0.05$, with respect to the pre-test.

Table 2. Quality of life questionnaire (SF36) scores

\begin{tabular}{cccc}
\hline Aspects & Pre-test & Mid-test & Post-test \\
\hline Emotional Dimension & $8.3 \pm 16.7$ & $100 \pm 00$ & $100 \pm 00^{* *}$ \\
Functional capacity & $48.8 \pm 2.5$ & $93.8 \pm 9.5^{*}$ & $97.5 \pm 5^{*}$ \\
Physical aspects & $18.8 \pm 23.9$ & $93.8 \pm 12.5^{*}$ & $99.8 \pm 0.5^{*}$ \\
Pain & $42 \pm 22.7$ & $89 \pm 13.6^{*}$ & $89 \pm 13.6^{*}$ \\
General health status & $31.8 \pm 23.1$ & $77.8 \pm 19.8^{*}$ & $77.8 \pm 25^{*}$ \\
Vitality & $26.3 \pm 22.9$ & $85 \pm 10.8^{*}$ & $90 \pm 4.1^{*}$ \\
Social aspects & $34.4 \pm 25.8$ & $96.9 \pm 6.3^{*}$ & $93.8 \pm 7.2^{*}$ \\
Mental health & $31 \pm 26.8$ & $86 \pm 10.6^{*}$ & $82 \pm 6.9^{*}$ \\
\hline
\end{tabular}

Note: ${ }^{*} p \leq 0.05$, with respect to the pre-test. ${ }^{* *} p \leq 0.01$, with respect to the pre-test.

Table 3. International Physical Activity Questionnaire results

\begin{tabular}{ccc}
\hline & Pre-test & Mid-test \\
\hline IPAQ (Kcal/weekly) & $3971 \pm 4645.6$ & $6726.1 \pm 5306.6^{*}$ \\
RPE & $6.8 \pm 0.5$ & $7.3 \pm 0.5$ \\
\hline
\end{tabular}

Note: IPAQ- international physical activity questionnaire, RPE- rating of perceived exertion. ${ }^{*} p \leq 0.05$, with respect to the pre-test. ${ }^{* *} \mathrm{p} \leq 0.01$, with respect to the pre-test.

The t-test identified a significant difference $(p=0.001)$ higher at post-test $(100 \pm 0)$ than the pre-test $(8.3 \pm 16.7)$ (table 2$)$.

The level of physical activity was measured using the IPAQ questionnaire with the activity time converted Kcal through the Bushman equation ${ }^{(27)}$. When we evaluated the general caloric expenditure, we observed a significant increasing from the pre-test to mid-test $(p=0.02)$ and from the pre-test to the post-test $(p=0.01)$. No significant difference was found between the mid-test and post-test ( $p>0.05)$. The RPE assessment did not present a significant difference between the moments $(p=0.48)$ (table 3$)$.

\section{DISCUSSION}

The objective of this study was to evaluate the effect of a functional training program on the BMI, WC, QOL and physical activity level in obese women with depression. As main result, we found that even in the absence of weight and BMI changes, QOL and physical activity level increased significantly and remained high in the second month.

Conventional two months functional training has been shown to affect positively the BMI and WC variables ${ }^{(31)}$. However, in the present study, only WC demonstrated significant changes. The WC is directly linked to the incidence of metabolic and cardiovascular diseases, being circumferences above $88 \mathrm{~cm}$ for women considered harmful to health ${ }^{(24)}$. Although the average value at the end of the second month (post-test) for WC was $96.25 \mathrm{~cm}$, which still represents health risks, we highlight the decrease of $8.7 \%$ in relation to the pre-test. This drop, besides being significant, demonstrates beneficial effect that the functional training brings to the participants.

In a recent study ${ }^{(32)}$, demonstrated that 6 weeks of functional training was due to increase the basal metabolism of sedentary women without significant changes in their body composition. In study ${ }^{(32)}$ the basal metabolism was evaluated indirectly through the composition of expired gases. In the present study we evaluated the weekly caloric expenditure and found significant changes between the pre-test and mid-test, and pre-test and post-test. This increase and maintenance of weekly caloric expenditure demonstrates a greater engagement of participants in voluntary activities during the week. It has been reported that the practice of physical activity has the ability to alter the behavior of individuals in a way that expresses a more active behavior, thanks to the changes caused in the control nuclei of the habit ${ }^{(33)}$. Although 
studies have focused on the effect of exercise on QOL through the SF-36 questionnaire and found positive results( ${ }^{(34,35)}$, it is not unanimous that physical exercise can improve the $\mathrm{QOL}$ in women ${ }^{(36)}$. Although depression is a rising disease, studies that investigate the effects of this pathology on young and obese women are scarce ${ }^{(37)}$.

In the present study, it was found that all dimensions of the SF-36 questionnaire improved from the pre-test to the mid-test and remained elevated at the post-test. This is a positive effect of physical exercise on aspects related to QOL, even in people with depression and obesity, which are factors known to negatively influence the $\mathrm{QOL}^{(13)}$. There are several factors that may be related to the improvement of depressive and mood symptoms, which affect aspects of QOL in general. These factors include psychological and physiological factors and are influenced by physical activity ${ }^{(13)}$. Among the psychological factors we highlight the following theories: Hypothesis of distraction, Theory of self-efficacy and Hypothesis of social interaction $^{(13)}$. Among the physiological factors, we highlight the following hypotheses: the monoamine hypothesis, endorphin hypothesis and thermogenesis hypothesis ${ }^{(13)}$. It is more likely that the practice of regular physical activity crosses between these theories, influencing as much in the improvements of the psychological as in the physiological aspects.

The main limitation in this study was sample size, which in too small sample size is difficult to find significant relationships from the data, as statistical tests normally require a larger sample size to ensure a representative distribution of the population and to be considered representative of groups of people to whom results will be generalized or transferred. There is a necessity to continue the study on a larger group of obese depressed women to confirm the results of this study. Future studies should investigate different aspects among men and women obese depressed.

\section{CONCLUSION}

The results found in this study suggest that the effect of personalized functional training during two months has a strong influence on the depressive state in obese women, promoting improvements in all aspects in the SF-36 questionnaire. We also found that this improvement cannot be explained only by morphological changes, since only the WC variable presented a significant change, but rather by a complex interaction between psychological and physiological factors.

\section{AUTHOR'S CONTRIBUTION:}

Acquisition of data and drafting the manuscript: JFB, DP, DT, JBP, VEG; Analyzed and interpreted of data: JFB, SA; Review the literature and wrote: DP, DT, JBP, VEG, SA; Approved final of the version to be published: JFB, DP, DT, JBP, VEG, SA.

\section{CONFLICT OF INTEREST:}

Nothing to declare.

\section{REFERENCES}

1. Lehtinen V, Joukamaa M. Epidemiology of depression: prevalence, risk factors and treatment situation. Acta psychiatrica Scandinavica Supplementum. 1994;377:7-10.

2. Ahmadi S, Heyrani A, Yoosefy B. Prevalence of body shape dissatisfaction and body weight dissatisfaction between female and male students. Journal of Physical Education and Sport. 2018;18(4):2264-2271.

3. Ahmadi S, Jabari N, Jamali M, Moradi J, Sadeghi A. Body dissatisfaction and mental health of competitive and recreational male bodybuilders. World Applied Sciences Journal. 2013;21(1):58-62.

4. Rozenthal M, Laks J, Engelhardt E. Aspectos neuropsicológicos da depressão. Revista de Psiquiatria. 2004;26(2):204-12.

5. Seligman ME. Desamparo: sobre depressão, desenvolvimento e morte. São Paulo: Hucitec. 1977.

6. Weissman MM, Olfson M. Depression in women: implications for health care research. Science. 1995;269(5225):799-801.

7. Pimenta AM, Sánchez-Villegas A, Bes-Rastrollo M, López CN, MartínezGonzález MÁ. Relationship between body image disturbance and incidence of depression: the SUN prospective cohort. BMC public health. 2009;9(1):1.

8. Darvishi M, Ahmadi S, Hierani A, Jabari N. Effects of motor imagery and maximal isometric action on grip strength of elderly men. World Applied Sciences Journal. 2013;24(4):556-560.

9. Hryhorczuk C, Sharma S, Fulton SE. Metabolic disturbances connecting obesity and depression. Frontiers in neuroscience. 2013;7:177.

10. Yektayar M, Saham M, Ahmadi S, Khodamoradpoor M. Effect of Rhythmic Aerobic Training on Mood Status Profile and Salivary Alpha Amylase in Non-athlete Students. Archives of Applied Science Research. 2012;4(5):2184-2190.

11. Pate RR, Pratt M, Blair SN, Haskell WL, Macera CA, Bouchard C, et al. Physical activity and public health: a recommendation from the Centers for Disease Control and Prevention and the American College of Sports Medicine. Jama. 1995;273(5):402-7.

12. Bruffaerts R, Vilagut G, Demyttenaere K, Alonso J, AlHamzawi A, Andrade $\mathrm{LH}$, et al. Role of common mental and physical disorders in partial disability around the world. The British Journal of Psychiatry. 2012;200(6):454-61.

13. Edwards MK, Loprinzi PD, editors. Effects of a sedentary behavior-inducing randomized controlled intervention on depression and mood profile in active young adults. Mayo Clinic Proceedings; 2016: Elsevier.

14. Ahmadi S, Uchida MC, Gutierrez GL. Physical performance tests in male and female sitting volleyball players: pilot study of Brazilian national team. Asian Journal of Sports Medicine. 2019;10(2):e85984.

15. Ahmadi S, Brietzke C, Silveira R, do Prado RCR, Brietzke R, Aguiar SS, Asano RY, Coelho-Júnior HJ. Aspects of physical training related with upper respiratory tract infections: a review. Manual Therapy, Posturology \& Rehabilitation Journal. 2018;16(568):1-8.

16. Williams DM. Exercise, affect, and adherence: an integrated model and a case for self-paced exercise. Journal of Sport and Exercise Psychology. 2008;30(5):471-96.

17. Byrne A, Byrne D. The effect of exercise on depression, anxiety and other mood states: a review. Journal of psychosomatic research. 1993;37(6):565-74.

18. Aguiar SS, Ahmadi S, Silveira R, do Prado RCR, Castro HO, Asano RY, CoelhoJúnior HJ. Nitric oxide and physical exercise: modulations in physiological systems during elderly. Manual Therapy, Posturology \& Rehabilitation Journal. 2018;16(614):1-8.

19. Eyigor S, Karapolat H, Durmaz B. Effects of a group-based exercise program on the physical performance, muscle strength and quality of life in older women. Archives of Gerontology and Geriatrics. 2007;45(3):259-71.

20. Palmer AK, Duncan KC, Ayalew B, Zhang W, Tzemis D, Lima V, et al. "The way I see it": the effect of stigma and depression on self-perceived body image among HIV-positive individuals on treatment in British Columbia, Canada. AIDS care. 2011;23(11):1456-66. 
21. Da Silva DTC, Silva KDS, Ahmadi S, Teixeira LFM. Indoor-cycling classes: Is there a difference between what instructors predict and what practitioners practice? Journal of Physical Education and Sport. 2019;19(1):772-780.

22. Beckham SG, Harper M. Functional training: fad or here to stay? ACSM's Health \& Fitness Journal. 2010;14(6):24-30.

23. Weiss $T$, Kreitinger J, Wilde $H$, Wiora $C$, Steege $M$, Dalleck L, et al. Effect of functional resistance training on muscular fitness outcomes in young adults. Journal of Exercise Science \& Fitness. 2010;8(2):113-22.

24. Dobbelsteyn C, Joffres M, MacLean DR, Flowerdew G. A comparative evaluation of waist circumference, waist-to-hip ratio and body mass index as indicators of cardiovascular risk factors. The Canadian Heart Health Surveys. International journal of obesity. 2001;25(5):652.

25. Lean M, Han T, Morrison C. Waist circumference as a measure for indicating need for weight management. Bmj. 1995;311(6998):158-61.

26. Lee PH, Macfarlane DJ, Lam T, Stewart SM. Validity of the international physical activity questionnaire short form (IPAQ-SF): A systematic review. International Journal of Behavioral Nutrition and Physical Activity. 2011;8(1):115.

27. Bushman BA. How can I use METs to quantify the amount of aerobic exercise?: LIPPINCOTT WILLIAMS \& WILKINS 530 WALNUT ST, PHILADELPHIA, PA 19106-3621 USA; 2012.

28. Lins L, Carvalho FM. SF-36 total score as a single measure of health-related quality of life: Scoping review. SAGE open medicine. 2016;4:2050312116671725.

29. Borresen J, Lambert MI. The quantification of training load, the training response and the effect on performance. Sports medicine. 2009;39(9):779-95.
30. Heirani A, Ahmadi S. Evaluation and Measurement in Physical Education. Kermanshah: Razi University Press. 2012.

31. Grant S, Todd K, Aitchison T, Kelly P, Stoddart D. The effects of a 12week group exercise programme on physiological and psychological variables and function in overweight women. Public Health. 2004;118(1):31-42.

32. Stavres J, Zeigler MP, Pasternostro Bayles M. Six Weeks of Moderate Functional Resistance Training Increases Basal Metabolic Rate in Sedentary Adult Women. International Journal of Exercise Science. 2018;11(2):32-41.

33. Thøgersen-Ntoumani $C$, Ntoumanis $N$. The role of self-determined motivation in the understanding of exercise-related behaviours, cognitions and physical self-evaluations. Journal of sports sciences. 2006;24(4):393-404.

34. Barrett C, Smerdely P. A comparison of community-based resistance exercise and flexibility exercise for seniors. Australian Journal of Physiotherapy. 2002;48(3):215-9.

35. Ahmadi S, Heirani A, Jabari N. Physical education and gender influence the mental health. World Applied Sciences Journal. 2013;28(3):408410.

36. Asbury EA, Chandrruangphen $P$, Collins $P$. The importance of continued exercise participation in quality of life and psychological well-being in previously inactive postmenopausal women: a pilot study. Menopause. 2006;13(4):561-7.

37. Heesch KC, van Gellecum YR, Burton NW, van Uffelen JG, Brown WJ. Physical activity, walking, and quality of life in women with depressive symptoms. American Journal of Preventive Medicine. 2015;48(3):281-91. 